\title{
The role of technology in the management of Diabetes mellitus [Letter]
}

This article was published in the following Dove Press journal: Patient Preference and Adherence

\section{Inayat Hussain Khan \\ Azhar Ramzan Bilal}

Faculty of Medicine, St George's Hospital Medical School, London, UK
Correspondence: Inayat Hussain Khan Faculty of Medicine, St George's Hospital Medical School, Cranmer Terrace, London SWI7 ORE, UK

Tel +447597827728

EmailmI506I3I@sgul.ac.uk

\section{Dear editor}

We read this article by Khurana et $\mathrm{al}^{1}$ with great interest. It is encouraging to see a study which explored how adherence in patients with Type 2 Diabetes mellitus could potentially be improved.

Diabetes is a condition affecting an increasing number of people and the macrovascular and microvascular changes are damaging to long term health, predisposing to vascular events such as heart attacks and strokes. ${ }^{2}$

Adherence to treatment plans is essential for good glycaemic control and to prevent such complications. A study found that effective communication between doctors and patients is key to ensuring adherence to individual treatment plans but of course this does not always take place. ${ }^{3}$ This current study ${ }^{1}$ evaluated how technology can help to bridge this gap in the management of chronic conditions like diabetes where treatment is lifelong and complex. Khurana et $\mathrm{al}^{1}$ showed that there is an appetite amongst patients for better use of technology to help manage chronic conditions; more than $80 \%$ of the participants surveyed in this study were interested in using electronic methods to assist them in managing their diabetes.

Despite these promising findings, we have identified some limitations that need to be addressed in order to assess the applicability of technology in the management of chronic conditions. For instance, we note that the recruitment of participants for this study was done through advertisements online and on newspapers. This may have introduced selection bias into this sample, as individuals who respond to such advertisements are more likely to be conscious about their health and positive about the use of technology and this may be reflected in the results.

Similarly, these advertisements through newspapers and through the internet are more likely to exclude those with limited English proficiency (LEP). In the US, Latinos make up the largest minority population and also make up a huge proportion of those with LEP. Steinberg et $\mathrm{al}^{4}$ evaluated 48 interviews of Latina mothers with LEP and found that navigating the healthcare system for these individuals can be a "battle" and is one of the reasons for huge inequalities in healthcare provision. It is therefore imperative that the use of technology such as apps does not create further inequalities in healthcare provision.

There are 318,000 apps available to help individuals manage their own health. ${ }^{5}$ Thus, shifting the role of doctors and other primary care staff such as specialist diabetic nurses to these smartphone platforms can seem tempting and even a sign of 
patient empowerment. Although this study highlights some positive attitudes to technology in managing diabetes it is important that this approach is suitable for a wide range of patients including those with LEP.

We, therefore, argue that to properly measure the applicability of technology in primary care settings, future studies should take these potential sources of selection bias into consideration and recruit through various outlets and possibly even at point of care to ensure that the views of a representative population including those with LEP are taken into account.

\section{Disclosure}

The authors report no conflicts of interest in this communication.

\section{References}

1. Khurana L, Durand E, Gary S, et al. Mechanisms for improving diabetes patient-provider communication through optimal use of e-clinical technologies. Patient Preference and Adherence. 2019;13:981-992. doi:10.2147/ PPA.S207008

2. Chen R, Ovbiagele B, Feng W. Diabetes and stroke: epidemiology, pathophysiology, pharmaceuticals and outcomes. The American Journal of the Medical Sciences. 2016;351(4):380-386. doi:10.1016/j. amjms.2016.01.011

3. Haskard Zolnierek K, DiMatteo M. Physician communication and patient adherence to treatment: a meta-analysis. Medical Care. 2009;47(8):826-834. doi:10.1097/MLR.0b013e31819a5acc

4. Steinberg E, Valenzuela-Araujo D, Zickafoose J, Kieffer E, DeCamp L. The "battle" of managing language barriers in health care. Clinical Pediatrics. 2016;55(14):1318-1327. doi:10.1177/0009922816629760

5. Aitken M, Clancey B, Nass D The Growing Value of Digital Health. New Jersey, USA: IQVIA Institute for Human Data Science; 2017. [2019-06-28]. Evidence and Impact on Human Health and the Healthcare System. Available from: https://www.iqvia.com/institute/ reports/the-growing-value-of-digital-health. Accessed 28 June, 2019.

\begin{abstract}
Dove Medical Press encourages responsible, free and frank academic debate. The content of the Patient Preference and Adherence 'letters to the editor' section does not necessarily represent the views of Dove Medical Press, its officers, agents, employees, related entities or the Patient Preference and Adherence editors. While all reasonable steps have been taken to confirm the content of each letter, Dove Medical Press accepts no liability in respect of the content of any letter, nor is it responsible for the content and accuracy of any letter to the editor.
\end{abstract}

\section{Publish your work in this journal}

Patient Preference and Adherence is an international, peer-reviewed, open access journal that focusing on the growing importance of patient preference and adherence throughout the therapeutic continuum. Patient satisfaction, acceptability, quality of life, compliance, persistence and their role in developing new therapeutic modalities and compounds to optimize clinical outcomes for existing disease states are major areas of interest for the journal. This journal has been accepted for indexing on PubMed Central. The manuscript management system is completely online and includes a very quick and fair peer-review system, which is all easy to use. Visit http:// www.dovepress.com/testimonials.php to read real quotes from published authors. 